\title{
OBSERVAÇÕES SOBRE ATIVIDADE DE MOSQUITOS CULICIDAE EM MATA PRIMITIVA DA ENCOSTA NO VALE DO RIBEIRA, SÃO PAULO, BRASIL*
}

\author{
Oswaldo Paulo Forattini** \\ Almério de Castro Alves** \\ Délsio Natal** \\ Jair Lício Ferreira Santos**
}

FORATTINi, O.P. et al. Observaçóes sobre atividade de mosquitos Culicidae em mata primitiva da encosta no Vale do Ribeira, São Paulo, Brasil. Rev. Saúde públ., S. Paulo, $20: 1-20,1986$

RESUMO: Relatam-se observações sobre o ciclo diário de atividade culicídea em ambiente primitivo da floresta perenifólia higrófila da encosta, do Sistema da Serra do Mar, no Vale do Ribeira, Estado de São Paulo, Brasil. Com periodicidade bimensal, e no período de dois anos, foram levadas a efeito coletas de vinte e cinco horas ininterruptas com o emprego de isca humana, bem como a utilização de armadilhas tipo Shannon operadas dentro e fora do ambiente florestal. Os resultados evidenciaram acentuada dominância de $A n$. cruzii, que se manteve durante todos os meses do ano mesmo naqueles de menor atividade culicídea. A influência crepuscular evidenciou-se pela nítida ocorrência de picos endocrepusculares para An. cruzii e An. bellator, seguidos imediatamente por outros, de menor intensidade, caracterizando assim ritmo que se propõe chamar de paracrepuscular. Ambas essas espécies de Kerteszia apresentaram atividade contínua para a isca humana, no período das 24 horas. $C x$. sacchettae mostrou-se nitidamente noturna e com ritmo eocrepuscular. Ae. serratus e Ps. ferox revelaram-se essencialmente diurnos, com certa tendência ao ritmo paracrepuscular porém, até onde foi possível observar, de maneira incompleta e limitado ao crepúsculo matutino. A atividade ininterrupta, aliada à densidade e dominância de $A n$. cruzii reafirma sua importância epidemiológica e a torna uma das feições que caracteriza - ambiente primitivo supracitado.

UNITERMOS: Culicidae. Vale do Ribeira, SP, Brasil. Ecologia. Anopheles cruzii. Anopheles bellator..

\section{INTRODUÇÃO}

Os estudos sobre os hábitos da fauna culicídea têm dedicado atenção à atividade hematófaga de seus componentes. Nesse particular tem-se objetivado observar as frequiências horárias das formas adultas e seu possível caráter rítmico. Ešte, revelando-se variável de acordo com as populações consideradas, constituiu-se aspecto diferencial, utilizável para melhor compreensão das implicações epidemiológicas consequientes.

Desde que esse comportamento, embora sob comando endógeno, está sensivel- mente sujeito a influências exógenas, torna-se particularmente importante observá-lo em vários tipos de ambiente. $\mathrm{E}$ tanto naqueles resultantes das alterações produzidas pela atividade humana, como no meio natural primitivo ou pouco modificado.

Em publicação anterior relatou-se observações que foram levadas a efeito em mata residual, como etapa de programação que se destina ao estudo da atividade culicídea (Forattini e col. ${ }^{6}, 1981$ ). Tais pesquisas, realizadas na área do $\mathrm{Va}$ -

\footnotetext{
* Realizado com auxílio financeiro da Fundacão de Amparo a Pesquisa do Estado de São Paulo FAPESP (Processo: 04 Biologicas 81/0150-0) e Financiadora de Estudos e Projetos - FINEP/ FNDCT (Convenio Ref. B/76/80/238/00/00).

** Do Departamento de Epidemiologia da Faculdade de Saúde Pública da Universidade de São Paulo - Av. Dr. Arnaldo, 715 - 01255 - São Paulo, SP - Brasil.
} 
FORATTINI, O.P. et al. Observações sobre atividade de mosquitos Culicidae em mata primitiva da encosta no Vale do Ribeira. São Paulo, Brasil. Rev. Saúde públ., S. Paulo, 20: 1-20, 1986.

le do Ribeira, Estado de São Paulo, Brasil, implicam sua repetição em outros ambientes. Em se tratando dessa mesma região, cujas características já foram descritas em outra publicação, importa considerar também as áreas de revestimento florestal mais preservado. Nestas, fundamentalmente, distinguem-se dois tipos, ou seja, o das matas que revestem o terreno acidentado da encosta montanhosa e 0 das que se desenvolvem em níveis baixos representados pela planície (Forattini e col. ${ }^{5}, 1978$ ).

Assim sendo, e com o mesmo interesse em observar o comportamento da fauna culicídea em relação à isca humana, seguiu-se orientação análoga à adotada nas pesquisas supracitadas e feitas em mata residual. Da mesma forma, e com finalidade comparativa, realizaram-se verificações simultâneas mediante o emprego de outros processos de coleta. Dessa maneira, no presente trabalho objetiva-se relatar os resultados obtidos com observações levadas a efeito em ambiente florestal preservado da encosta.

\section{CARACTERISTICAS LOCAIS}

O local que serviu de sede para a realização destas observações foi representado pelo sítio Itapuã, no município de Cananéia. "Situa-se próximo à vila de Itapitangui da qual dista cerca de dois quilômetros, pela estrada que liga essa localidade à de Ariri. $O$ aspecto corresponde ao da mata perenifolia da encosta que, nesta região, cobre as vertentes da Serra de Itapitangui e em cujo sopé situa-se a área estudada. Os terrenos planos que se defrontam ao local supracitado são atravessados pelo rio que leva o mesmo nome do referido maciço montanhoso. Acompanha esse curso de água, revestimento vegetal como representante residual da mata primitiva da planície. $O$ restañte dessa superfície é aberta e apresenta vegetação secundária baixa, áreas cultivadas ou com sucessão degradada conseqüentes a alterações de que foram objeto. Assim, a escolha do local para a execução destes trabalhos obedeceu a critério que visava o ambiente da floresta primitiva da encosta. Dessa maneira, selecionou-se área do mencionado sítio Itapuã situada à margem da rodovia referida e no início do aclive montanhoso. A Figura 1 mostra a localização da região e da área sede destas observações, além dos aspectos locais.

Os objetivos desta escolha foram, como se referiu, observar o comportamento culicídeo no ambiente florestal primitivo da encosta, em relação à isca humana. As características desse ambiente são as da mata perenifólia higrófila rica em bromélias e epífitas em geral. Dado o acentuado aclive do terreno, o ecótopo representado pela copa arbórea situa-se em relativa proximidade com o do solo. No decurso destas investigações, decorrido o período de aproximadamente um ano a contar de seu início, verificou-se a ocorrência de uma única alteração do ambiente, representada por desmatamento levado a efeito em terreno vizinho. As Figuras 2 a 6 destinam-se a fornecer idéia sobre as mencionadas características locais e regionais.

\section{MATERIAL E METODOS}

A metodologia empregada foi a mesma já descrita detalhadamente, em trabalho anterior (Forattini e col. ${ }^{6}$, 1981). As coletas tiveram início em abril de 1980 , tendo-se prolongado até o mesmo mês de 1982. Em meados de 1981 deuse o desmatamento vizinho, mencionado em parágrafo anterior.

As coletas tiveram o mesmo ritmo bimensal, que incluiu duas semanas alternadas. Em cada uma procedeu-se à captura com isca humana com a duração de 25 horas ininterruptas, iniciada na terça-feira, às 10:00 encerrada às 11:00 
FORATTINI, O.P. et al. Observações sobre atividade de mosquitos Culicidae em mata primitiva da encosta no Vale do Ribeira, São Paulo, Brasil. Rev. Saúde públ., S. Paulo, 20: 1-20, 1986.

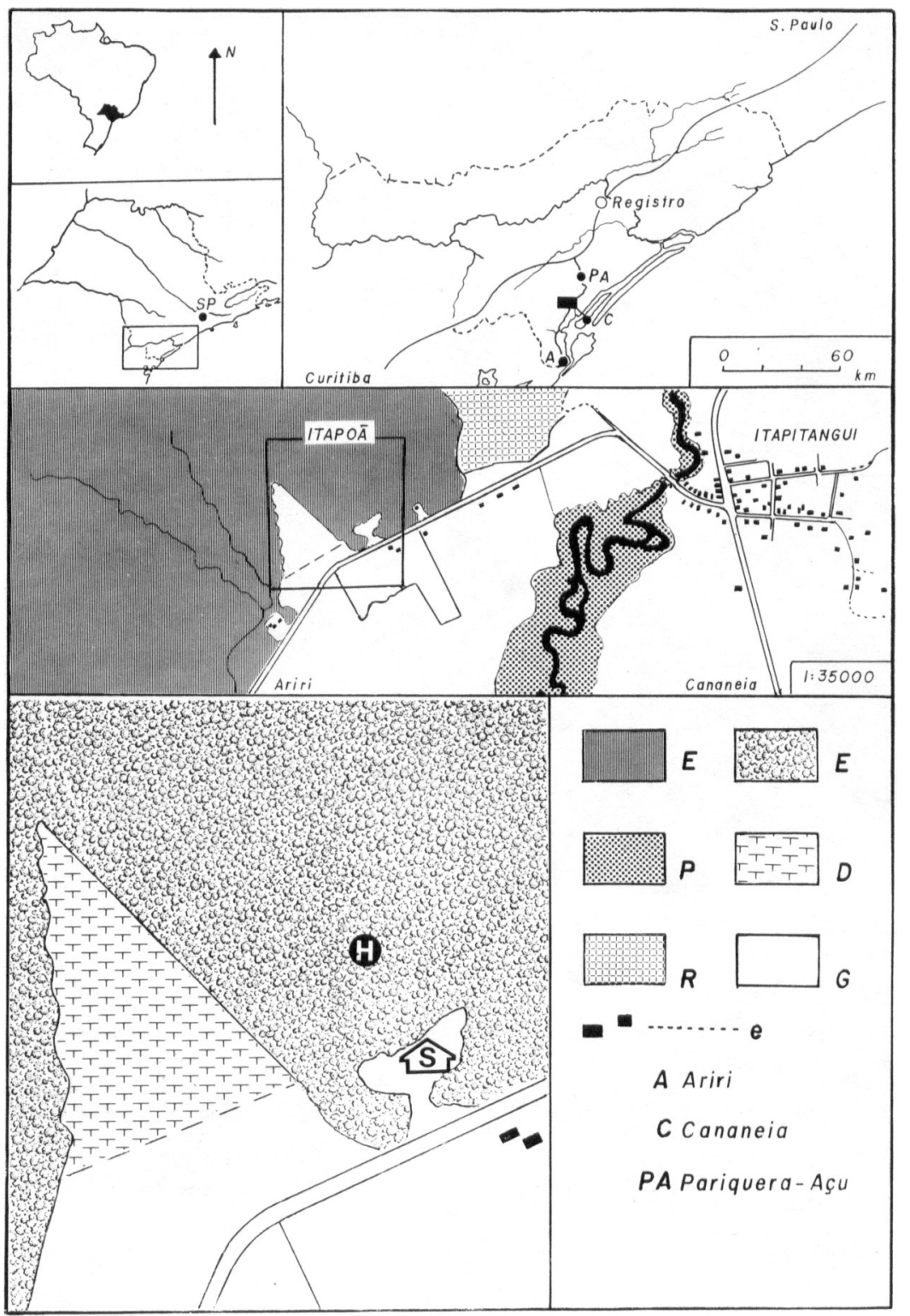

Fig. 1 - Representação esquemática da localização e características do sítio Itapuã. próximo da vila de Itapitangui no município de Cananéia. e da área estudada. $D$ - área desmatada.

E - mata primitiva da encosta.

e - edificacões e estradas secundárias.

G - terrenos abertos, cultivados, com vegetação secundária ou degradados.

H - localização da coleta com isca humana e armadilha tipo shannon.

$\mathbf{P}$ - mata residual da planície.

$\mathbf{R}$ - área reflorestada.

$S$ - localização da armadilha tipo Shannon. em local aberto.

SP - cidade de São Paulo. 
FORATTINI, O.P. et al. Observações sobre atividade de mosquitos Culicidae em mata primitiva da encosta no Vale do Ribeira, São Paulo, Brasil. Rev. Saúde públ., S. Paulo, 20; 1-20, 1986.
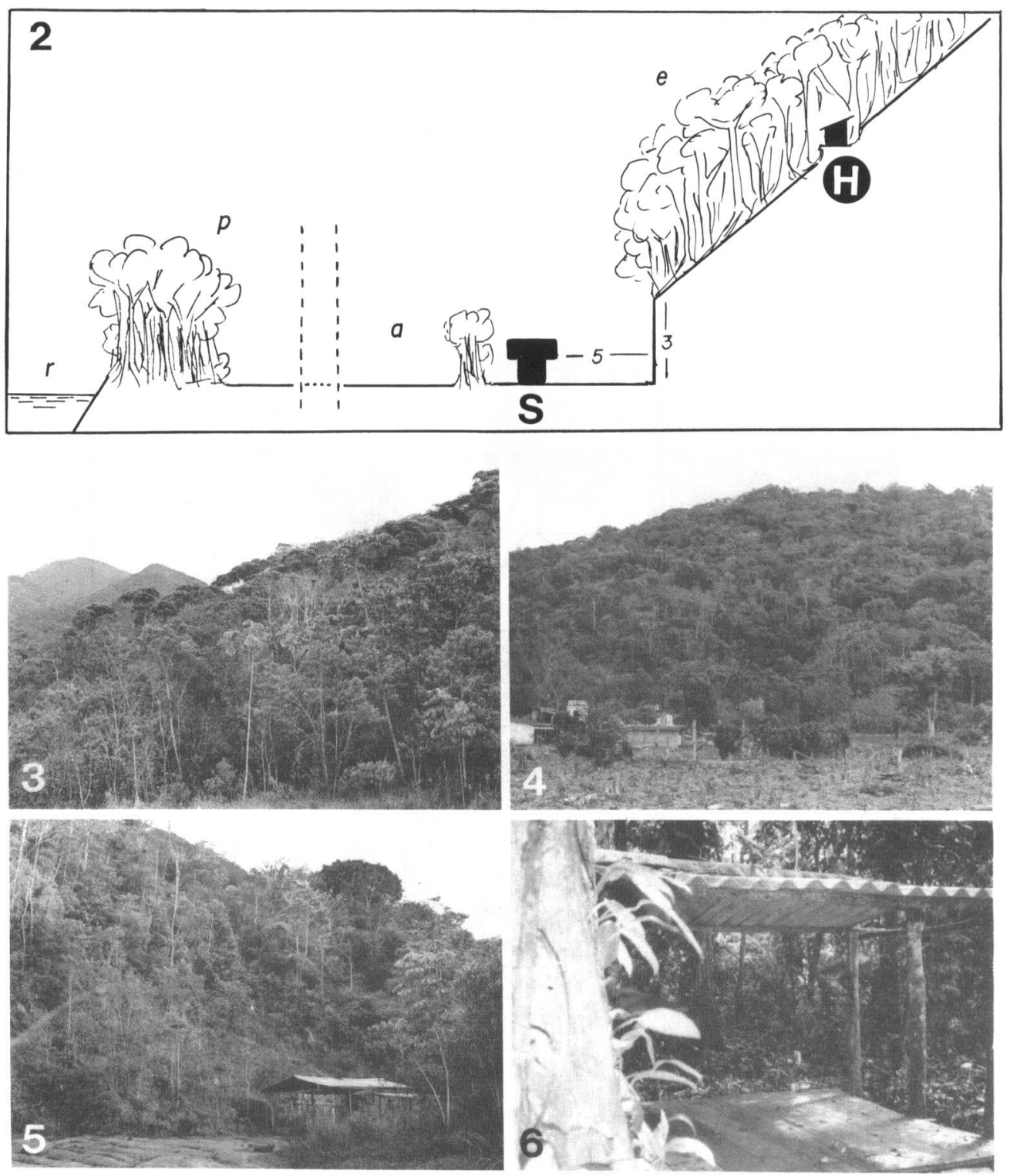

Fig. 2 - Representação esquemática do local de observaçōes no sítio Itapuã.

$\mathrm{H}$ - coleta com isca humana e armadilha tipo Shannon.

$S$ - armadilha tipo Shannon em local aberto.

a - estrada para Ariri.

e - mata primitiva da encosta.

p - mata residual da planície.

$\mathbf{r}$ - rio Itapitangui.

$3, \overline{5}$ - distâncias, em metros.

Figs. 3 e $4-$ Aspectos da mata primitiva da encosta no sítio Itapuã, onde foram levadas a $\in$ feito as observaçóes.

Fig. 5 - Local da armadilha tipo Shannon, no aberto.

Fig. 6 - Local da coleta com isca humana e da armadilha tipo Shannon, na mata. 
FORATTINI, O.P. et al. Observações sobre atividade de mosquitos Culicidae em mata primitiva da encosta no Vale do Ribeira, São Paulo, Brasil. Rev. Saúde públ., S. Paulo, 20: 1-20, 1986 .

do dia seguinte. Nessas mesmas semanas incluiu-se a realização de uma coleta manual mediante o emprego de duas armadilhas tipo Shannon com isca luminosa as quais, de maneira simultânea, foram operadas dentro e fora do ambiente florestal da encosta no período das 18:00 às 24:00 horas. Assim pois, o ritmo mensal das coletas compreendeu duas capturas com isca humana e quatro com armadilha tipo Shannon, todas realizadas nas mesmas semanas alternadas. Quanto à localização das últimas, aquela efetuada dentro da mata, o foi no mesmo local em que se procedia à captura com isca humana. A correspondente à área aberta foi realizada em clareira situada à margem da estrada e distante cerca de $5 \mathrm{~m}$ do barranco, de aproximadamente $3 \mathrm{~m}$ de altura, que marcava o início do aclive da encosta (Fig. 2).

No que concerne à identificação das espécies, a evolução dos estudos taxonômicos permitiu introduzir algumas alterações em relação aos critérios anteriormente adotados (Ward ${ }^{19}$, 1984; Gaffigan e Ward ${ }^{8}$, 1985). Em relação a Culex (Melanoconion), ao lado de elementos que permitiram a identificação de maior número de espécies, há que referir a descrição de $C x$. sacchettae e de $C x$. ribeirensis, correspondentes aos anteriormente identificados como $C x$. vomerifer e $C x$. crybda, respectivamente (Sirivanakarn e Jakob ${ }^{15}$, 1981; Forattini e Sallum, ${ }^{7}$ 1985). Embora se tenha podido destacar Cx. mollis, isso ocorreu quando já boa parte dos resutlados estavam computados. Em vista disso, neste trabalho essa espécie continua incluida em Culex (Culex) sp. No que concerne ao gênero Anopheles, é mantido aqui o nome $A n$. albitarsis, uma vez que a validade de $A n$. allopha permanece ainda sujeita a dúvidas (Oliveira e Deane ${ }^{13}$, 1984). Os anteriormente denominados $A n$. evansi e $A n$. noroestensis passam agora a ser aqui referidos como $A n$. strodei e $A n$. evansae, respec- tivamente. As espécies Runchomyia só puderam ser identificadas, com segurança, após concluída parte da computação dos dados, motivo pelo qual acham-se incluídas em Runchomyia (Runchomyia) sp. Da mesma forma, o encontro de evidências que permitiram constatar a presença de Aedes hastatus e Ae. oligopistus, faz com que esse fato deva ser levado em consideração nos dados atribuídos a $A$ e. serratus, uma vez que ainda não se dispõe de suficientes elementos para ampla diferenciação específica dos espécimens femininos dessas três espécies.

\section{RESULTADOS}

No período citado, ou seja, de abril de 1980 ao mesmo mês de 1982, as coletas forneceram o total global de 138.383 mosquitos. Nas Tabelas 1 e 2 pode-se verificar a distribuição específica desse material. Observa-se, assim, que oito espécies e dois grupos genéricos representaram mais de $95,0 \%$ do material coletado. É de se assinalar que cerca de $81,0 \%$ desse resultado foi fornecido por dois anofelinos Kerteszia, um dos quais, o Anopheles cruzii, participou com $77,0 \%$. O restante dos espécimens se distribuiram entre 77 espécies e 7 grupos genéricos. O franco predomínio de An. cruzii manteve-se nas três modalidades de captura empregadas. Os Sabethini somente compareceram na isca humana, ao passo que os outros somente foram obtidos nas armadilhas tipo Shannon. De qualquer maneira, a expressividade encontra-se praticamente restrita aos dois representantes do subgênero Kerteszia, em especial àquele supracitado. Assim sendo, e levàndo-se em conta seu reconhecido papel na veiculação da malária, merecerá àqui focalização especial o estudo do comportamento desses anofelinos. Por sua vez, a existência de dados concernentes à possibilidade de transmissão regional de arbovírus fez com que algumas 
FORATTINI, O.P. et al. Observações sobre atividade de mosquitos Culicidae em mata primitiva da encosta no Vale do Ribeira, São Paulo, Brasil. Rev. Saúde públ., S. Paulo, 20: 1-20, 1986.

outras espécies merecessem destaque. Entre elas selecionou-se Psorophora ferox e Culex sacchettae. Aquela por ter propiciado isolamento do vírus Rocio, e esta por representar, nas presentes observações, o subgênero Melanoconion, grupo de onde foram registrados isolamentos de diversos outros desses agentes virais (Lopes e col. ${ }^{11}$, 1981; Calisher e col..$^{2,3}$, 1982). Considerando-se que as armadilhas de Shannon somente foram impregadas em horas noturnas, a inclusão de Phoniomyia sp., Sabethes undosus e Wyeomyia confusa permitiu observar o comportamento essencialmente diurno desses sabetíneos. Quanto ao conjunto representado por Runchomya sp., a irregularidade e dificuldade em separar suas espécies não permitiu tratamento individual, ao menos nesta fase das atuais investigações. Dessa maneira, os mosquitos, cujo comportamento será objeto de descrição nos resultados da presente pesquisa, constituem conjunto que representa $90,1 \%$ do total de exemplares coletados.

TABELA 1

Distribuição, por tipo de coleta, das espécies mais frequientes no sítio Itapuã, no período de abril de 1980 a abril de 1982.(+)

\begin{tabular}{|c|c|c|c|c|c|c|c|c|}
\hline \multirow[t]{2}{*}{ Espécies } & \multicolumn{2}{|c|}{ Isca humana } & \multicolumn{2}{|c|}{$\begin{array}{l}\text { Armadilha } \\
\text { de Shannon } \\
\text { na mata }\end{array}$} & \multicolumn{2}{|c|}{$\begin{array}{l}\text { Armadilha } \\
\text { de Shannon } \\
\text { no aberto }\end{array}$} & \multicolumn{2}{|c|}{ Total } \\
\hline & $N$ & $\% *$ & $\mathbf{N}$ & $\% *$ & $\mathbf{N}$ & $\% *$ & $N$ & $\% *$ \\
\hline $\begin{array}{l}\text { Aedes (Ochlerotatus) serratus } \\
\text { Anopheles (Kerteszia) bella- }\end{array}$ & - & - & 234 & 1,1 & - & - & 234 & 0,2 \\
\hline tor & 2.857 & 4,0 & 211 & 3,3 & 1.781 & 3,9 & 5.349 & 3,9 \\
\hline An. (Ker.) cruzii & 44.973 & 62,7 & 19.135 & 89,8 & 42.362 & 93,4 & 106.470 & 76,9 \\
\hline $\begin{array}{l}\text { Culex (Melanoconion) sac- } \\
\text { chettae }\end{array}$ & 1.781 & 2,5 & 299 & 1,4 & - & - & 2.080 & 1,5 \\
\hline Phoniomyia davisi & 894 & 1,2 & - & - & 一 & 一 & 884 & 0,6 \\
\hline Phon'omyia sp. & 4.130 & 5,8 & - & - & 一 & - & 4.130 & 3,0 \\
\hline $\begin{array}{l}\text { Psorophora (Janthinosoma) } \\
\text { ferox }\end{array}$ & 1.176 & 1,6 & - & - & - & - & 1.176 & 0,8 \\
\hline $\begin{array}{l}\text { Runchomyia (Runchomyia) } \\
\text { sp. }(* *)\end{array}$ & 5.833 & 8,1 & - & - & - & - & 5.833 & 4,2 \\
\hline $\begin{array}{l}\text { Sabethes (Sabethinus) } \\
\text { undosus }\end{array}$ & 1.723 & 2,4 & - & - & - & - & 1.723 & 1,3 \\
\hline $\begin{array}{l}\text { Wyeomyia (Dendromyia) } \\
\text { confusa }\end{array}$ & 4.207 & 5,9 & - & - & 一 & - & 4.207 & 3,1 \\
\hline Outras & 4.174 & 5,8 & 936 & 4,4 & 1.187 & 2,6 & 6.297 & 4,5 \\
\hline Total & 71.738 & 100,0 & 21.315 & 100,0 & 45.330 & 99,9 & 138.383 & 100,0 \\
\hline
\end{tabular}

* Sobre o respectivo total geral.

** Incluindo $R u$. cerqueirai, $R u$. frontosa, $R u$. reversa e $R u$, theobaldi.

(+) Comparecimento de, pelo menos, $1,0 \%$ sobre o respectivo total geral. 
FORATTINI, O.P. et al. Observações sobre atividade de mosquitos Culicidae em mata primitiva da encosta no Vale do Ribeira, São Paulo, Brasil. Rev. Saúde públ., S. Paulo, 20: 1-20, 1986.

\section{TABELA 2}

Distribuição, por tipo de coleta, das espécies menos frequientes, no sítio Itapuã no período de abril de 1980 a abril de 1982.

\begin{tabular}{|c|c|c|c|c|c|c|c|c|}
\hline \multirow[t]{2}{*}{ Espécies } & \multicolumn{2}{|c|}{ Isca humana } & \multicolumn{2}{|c|}{$\begin{array}{l}\text { Armadilha } \\
\text { de Shannon } \\
\text { na mata }\end{array}$} & \multicolumn{2}{|c|}{$\begin{array}{c}\text { Armadilha } \\
\text { de Shannon } \\
\text { no aberto }\end{array}$} & \multicolumn{2}{|c|}{ Total } \\
\hline & $\mathbf{N}$ & $\% *$ & $\mathbf{N}$ & $\% *$ & $\mathbf{N}$ & $\% *$ & $\mathbf{N}$ & $\% *$ \\
\hline $\begin{array}{l}\text { Aedes (Ochlerotatus) scapularis } \\
\text { Ae. (Och.) grupo serratus (ser- }\end{array}$ & 198 & 4,7 & 77 & 8,2 & 168 & 14,1 & 443 & 7,0 \\
\hline ratus, hastatus ou oligopistus) & 611 & 14,6 & 一 & - & 69 & 5,8 & 680 & 10,8 \\
\hline Anopheles (Anopheles) intermedius & - & - & - & - & 25 & 2,1 & 25 & 0,4 \\
\hline $\begin{array}{l}\text { An. (Ano.) mediopunctatus } \\
\text { Coquillettidia (Rhynchotaenia) }\end{array}$ & 96 & 2,3 & 97 & 10,4 & 265 & 22,3 & 458 & 7,3 \\
\hline chrysonotum & 213 & 5,1 & 104 & 11,1 & 127 & 10,7 & 444 & 7,0 \\
\hline Cq. (Rhy) venezuelensis & - & 一 & 25 & 2,7 & 34 & 2,9 & 59 & 0,9 \\
\hline Culex (Culex) sp. & - & - & 149 & 15,9 & 一 & 一 & 149 & 2,4 \\
\hline Cx. (Melanoconion) ribeirensis & 一 & 一 & 32 & 3,4 & - & - & 32 & 0,5 \\
\hline Cx. (Mel.) sacchettae & 一 & 一 & - & - & 312 & 26,3 & 312 & 4,9 \\
\hline Cx. (Mel.) sp. & 一 & - & 86 & 9,2 & - & - & 86 & 1,4 \\
\hline & & & & & & & & \\
\hline $\begin{array}{l}\text { cocelaenus } \\
\text { Limatus durhami }\end{array}$ & $\begin{array}{l}70 \\
56\end{array}$ & 1,7 & 一 & - & - & - & $\begin{array}{l}70 \\
56\end{array}$ & $\begin{array}{l}1,1 \\
0.9\end{array}$ \\
\hline $\begin{array}{l}\text { Limatus durhami } \\
\text { Li. flavisetosus }\end{array}$ & $\begin{array}{r}56 \\
207\end{array}$ & 1,3 & - & - & - & - & $\begin{array}{r}56 \\
292\end{array}$ & $\begin{array}{l}0,9 \\
46\end{array}$ \\
\hline & 292 & 7,0 & 一 & - & - & - & $\begin{array}{r}292 \\
43\end{array}$ & $\begin{array}{l}4,6 \\
0.7\end{array}$ \\
\hline $\begin{array}{l}\text { Psorophora (Janthinosoma) albigenu } \\
\text { Ps (Jan.) ferox }\end{array}$ & 43 & 1,0 & $\overline{105}$ & $\overline{11}$ & $\overline{20}$ & - & $\begin{array}{r}43 \\
125\end{array}$ & 0,7 \\
\hline & - & - & $\begin{array}{r}105 \\
47\end{array}$ & $\begin{array}{r}11,2 \\
5,0\end{array}$ & 20 & 1,7 & $\begin{array}{r}125 \\
47\end{array}$ & $\begin{array}{l}2,0 \\
0,7\end{array}$ \\
\hline Sabethes (Sabethinus) aurescens & 49 & 1,2 & - & - & - & - & 49 & 0,8 \\
\hline Sa. (Sbn) intermedius & 82 & 2,0 & - & - & 一 & 一 & 82 & 1,3 \\
\hline Sa. (Sbn) soperi & 240 & 5,7 & - & - & 一 & 一 & 240 & 3,8 \\
\hline Sa. (Sabethoides) chloropterus & 49 & 1,2 & 一 & - & - & - & 49 & 0,8 \\
\hline Shannoniana fluviatelis & 206 & 4,9 & - & - & - & - & 206 & 3,3 \\
\hline Trichoprosopon pallidiventer & 118 & 2,8 & - & - & 一 & - & 118 & 1,9 \\
\hline Wyeomyia (Dendromyia) aporo- & & & & & & & & \\
\hline noma & 352 & 8,4 & - & - & - & - & 352 & 5,6 \\
\hline Wy. (Den.) confusa & - & 一 & 73 & 7,8 & - & - & 73 & 1,1 \\
\hline Wy. (Den.) personata & 45 & 1,1 & 一 & - & - & 一 & 45 & 0,7 \\
\hline Wy. (Den.) shannoni & 253 & 6,1 & - & - & - & - & 253 & 4,0 \\
\hline Wy. sp. & 787 & 18,8 & - & - & - & - & 787 & 12,5 \\
\hline Outras espécies & $414 a$ & 9,9 & $141 b$ & 15,1 & $167 \mathrm{c}$ & 14,1 & 722 & 11,5 \\
\hline Total & 4.174 & 99,8 & 936 & 100,0 & 1.187 & 100,0 & 6.297 & 99,9 \\
\hline
\end{tabular}

* sobre os respectivos totais gerais.

a - Ae. (Howardina) fulvithorax; Ae. (Och.) fluviatilis; Ae. (Och.) fulvus; Ae. (Och.) hortator ou Ae. (Och.) perventor; Ae. (Protomadeaya) argyrothorax; Ae. (Pro.) terrens; Cq. (Rhy.) juxtamansonia; $C q$. (Rhy.) nigracans; $C q$. (Rhy.) venezuelensis; $C x$. (Cux.) dolosus; $C x$. (Cux.) grupo coronator (coronator ou usquatus); $C x$. (Cux.) sp. (bidens, declarator, lygrus, mollis, nigripalpus); $C x$. (Mel.) misionensis; $C x$. (Mel.) pedroi; $C x$. (Mel.) ribeirensis; $C x$. (Mel.) spissipes; $C x$. (Mel.) taeniopus; $C x$. (Mel.) grupo atratus (trigeminatus); $C x$. (Mel.) sp. (abonnenci, coppenamensis, corentynensis, evansae, intrincatus, oedipus, galvaoi, pilosus); Cx. (Mel.) sp. (não determinado); Haemagogus (Stegoconops) capricornii; Mansonia (Mansonia) sp.; Ps. (Grabhamia) confinnis; Ps. (Jan.) discrucians; Sa. (Sabethes) albiprivus; Sa. (Sab.) cyaneus; Sa. (Sab.) purpurens; Sa. (Sab.) quasicyaneus); Sa. (Sab.) shannoni; Sa. (Sab.) tarsopus; Sa. sp. 
FORATTINI, O.P. et al. Observações sobre atividade de mosquitos Culicidae em mata primitiva da encosta no Vale do Ribeira, São Paulo. Brasil. Rev. Salide públ., S. Paulo, 20: 1-20, 1986.

Atividades horárias - A Tabela 3 expõe, por intervalos horários, os resultados das capturas bimensais, com o emprego de isca humana, de 25 horas ininterruptas. Foram assim executadas 50 dessas coletas, obtendo-se o total de 71.738 mosquitos como representantes das espécies mais frequientes.

Como era de se esperar, pôde-se verificar a atividade essencialmente diurna dos sabetíneos, representados por Phoniomyia sp., Sa. undosus e Wy. confusa, em contraste com a predominância noturna de $C x$. sacchettae. Quanto aos representantes do subgênero Kerteszia, foi observada sua atividade durante todas as horas, com acentuado pique nas horas correspondentes ao início da noite. Tais aspectos podem ser apreciados nos gráficos que compõem a Figura 7. O "efeito de intrusão" pôde ser verificado comparando-se as médias obtidas nos dois intervalos, inicial e final, correspondentes ao intervalo das $10: 00$ às $11: 00$ horas. Com isso, esse fenômeno tornou-se evidente apenas em relação a $A n$. bellator e An. cruzii.
Nas coletas com as armadilhas tipo Shannon foram obtidos os dados que se encontram na Tabela 4, para as espécies mais freqüentes e assim consideradas de acordo com os critérios adotados na Tabela 1. É possível assim verificar que, de maneira geral, o intervalo correspondente ao período das 19:00 às 20:00 horas foi o de maior rendimento tanto no interior da mata como no aberto. Fsse aspecto revelou-se mais evidente para as espécies dominantes, em especial modo An. cruzil. Observou-se também maior comparecimento no aberto do que na mata, uma vez que a média geral obtida nesta última resultou sensivelmente menor, ou seja, correspondendo a menos da metade do valor registrado no ambiente aberto. $E$ isso também mostrou-se nítido no que concerne às espécies dominantes. Quanto às demais, embora com presença discreta, foi possivel detectar maior ocorrência de $A e$. serratus e de $P$ s. ferox no meio intraflorestal, e praticamente igual para os dois ambientes, no caso de $C x$. sacchettae.

(continuação da nota da Tabela 2)

b - Ae. (Och.) fulvus; Ae. (Och.) hortator ou Ae. (Och.) perventor; Ae. (Pro.) argyrothorax; Ae. sp; An. (Ano.) intermedius; An. (Ano.) punctimacula; An. (Nyssorhynchus) oswaldoi; Cq. (Rhy.) juxtamansonia; $C x$. (Cux.) chidesteri; $C x$. (Cux.)dolosus; $C x$. (Cux.) grupo coronator (coronator ou usquatus); $C x$. (Lutzia) bigoti; $C x$. (Mel.) distinguendus; $C x$. (Mel.) missionensis; $C x$. (Mel.) pedroi; $C x$. (Mel.) taeniopus; $C x$. (Mel.) theobaldi; $C x$. (Mel.) zeteki; $C x$. (Mel.) grupo atratus (trigeminatus); $C x$. (Mel.) sp. (não determinado); Cx. (Microculex) sp.; Hg. (Con.) leucocelaenus; Li. flavisetosus; Ma. (Man.) sp.; Phoniomyia davisi; Ph. sp.; Ps. (Gra.) cingulata; Ps, (Jan.) albigenu; Ru. (Run.) sp.; Sa. (Sbn.) soperi; Sa. (Sbn.) undosus; Shannoniana fluviatilis; Tr. pallidiventer; $W y$. (Den.) aporonoma; Wy. (Den.) mystes; Wy. (Den.) personata.

c - Ae. (Och.) hortator ou Ae. (Och.) perventor; Ae. (Pro.) argyrothorax; Ae. (Pro.) terrens; An. (Nys.) oswaldoi; Cq. (Rhy.) albicosta; $C x$. (Cux.) dolosus; $C x$. (Cux.) grupo coronator (coronator ou usquatus); $C x$. (Cux.) sp. (bidens, declarator, lygrus, mollis, nigripalpus); $C x$. (Lut.) bigoti; Cx. (Mel.) misionensis; $C x$. (Mel.) ribeirensis; $C x$. (Mel.)taeniopus; $C x$. (Mel.) theobaldi; $C x$. (Mel.) zeteki; $C x$. (Mel.) grupo atratus (trigeminatus); $C x$. (Mel.) sp. (abonnenci; coppenamensis, corentynensis, evansae, intrincatus; oedipus, galvaoi cu pilosus); $C x$. (Mel.) sp. (näo determinado); Hg. (Con.) leucocelaenus; Li. durhami; Ma. (Man.) sp.; Ph. davisi; Ph. sp.; Ps. (Jan.) albigenu; Ru. (Run.) sp ; Shannoniana fluviatilis; Tr. pallidiventer; Uranotaenia (Uranotaenia) mathesoni; Vr. (Vra.) pulcherrima; $W y$. (Den.) confusa; $W y, \mathrm{sp}$. 
FORATTINI, O.P. et al. Observações sobre atividade de mosquitos Culicidae em mata primitiva da encosta no Vale do Ribeira, São Paulo, Brasil. Rev. Saúde públ., S. Paulo, 20: 1-20, 1986.

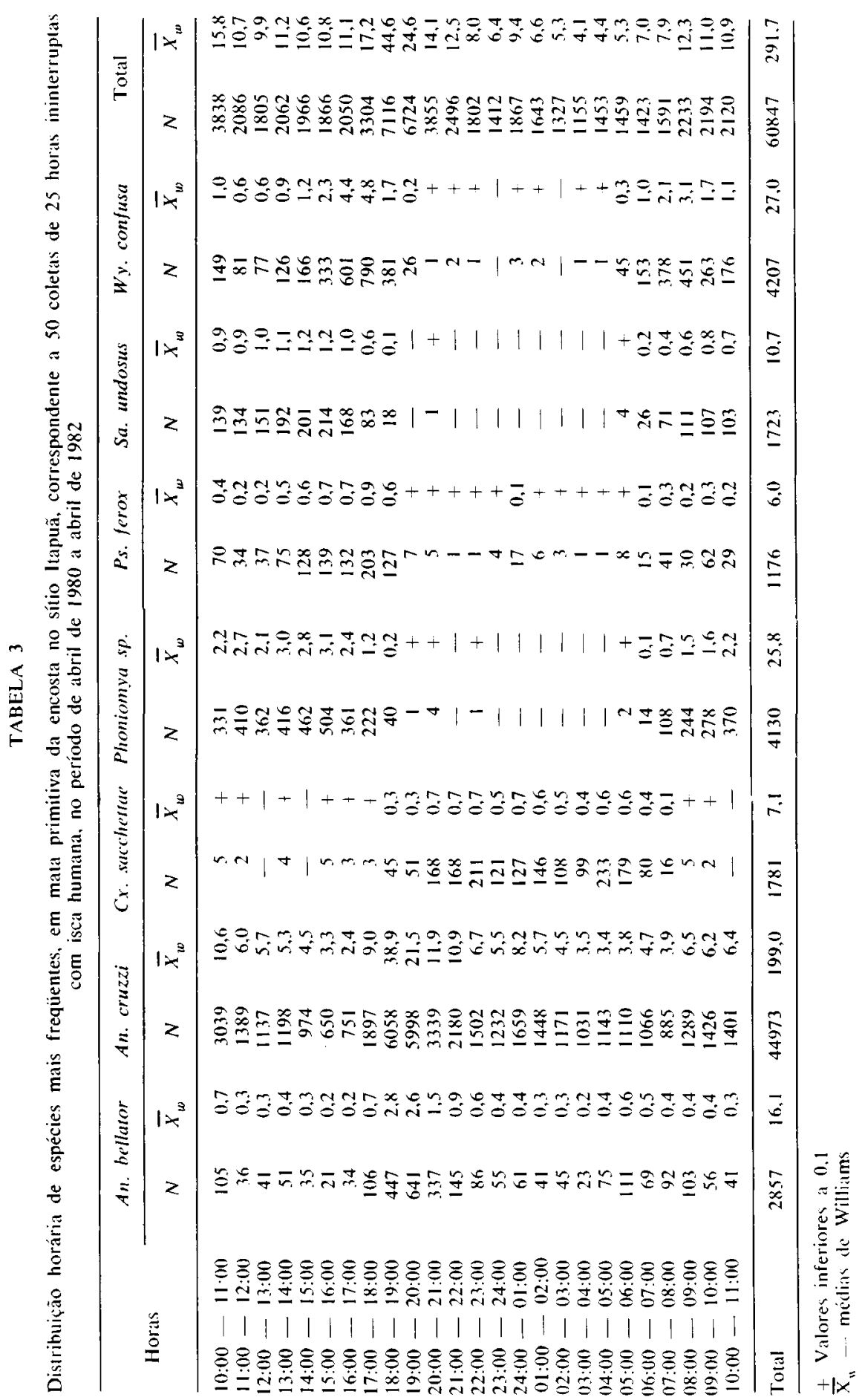


FORATTINI, O.P. et al. Observações sobre atividade de mosquitos Culicidae em mata primitiva da encosta no Vale do Ribeira, São Paulo, Brasil. Rev. Saúde públ., S. Paulo, 20: 1-20, 1936 .

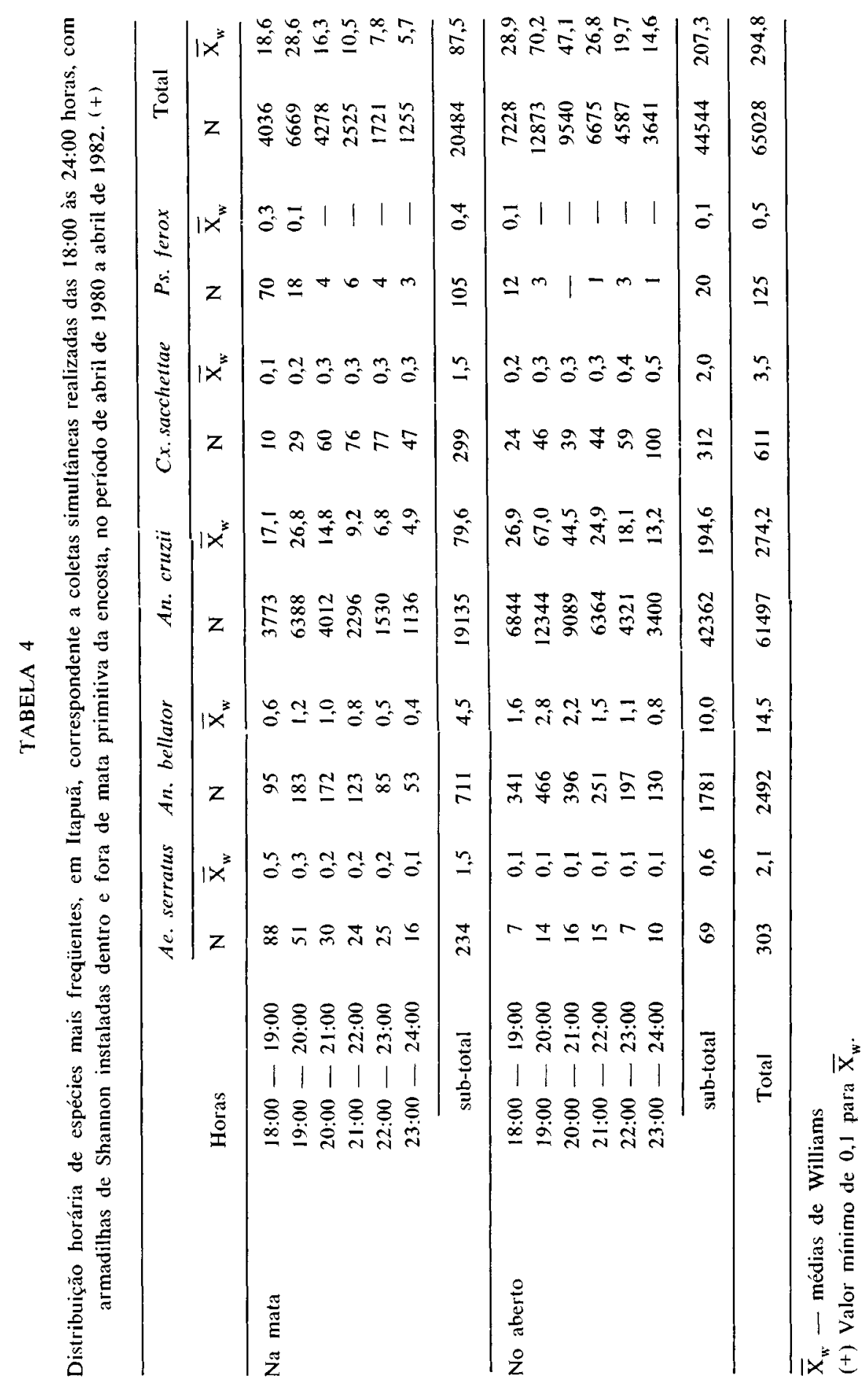


FORATTINI, O.P. et al. Observações sobre atividade de mosquitos Culicidae em mata primitiva da encosta no Vale do Ribeira, São Paulo, Brasil. Rev. Saúde públ., S. Paulo, 20: 1-20, 1986.

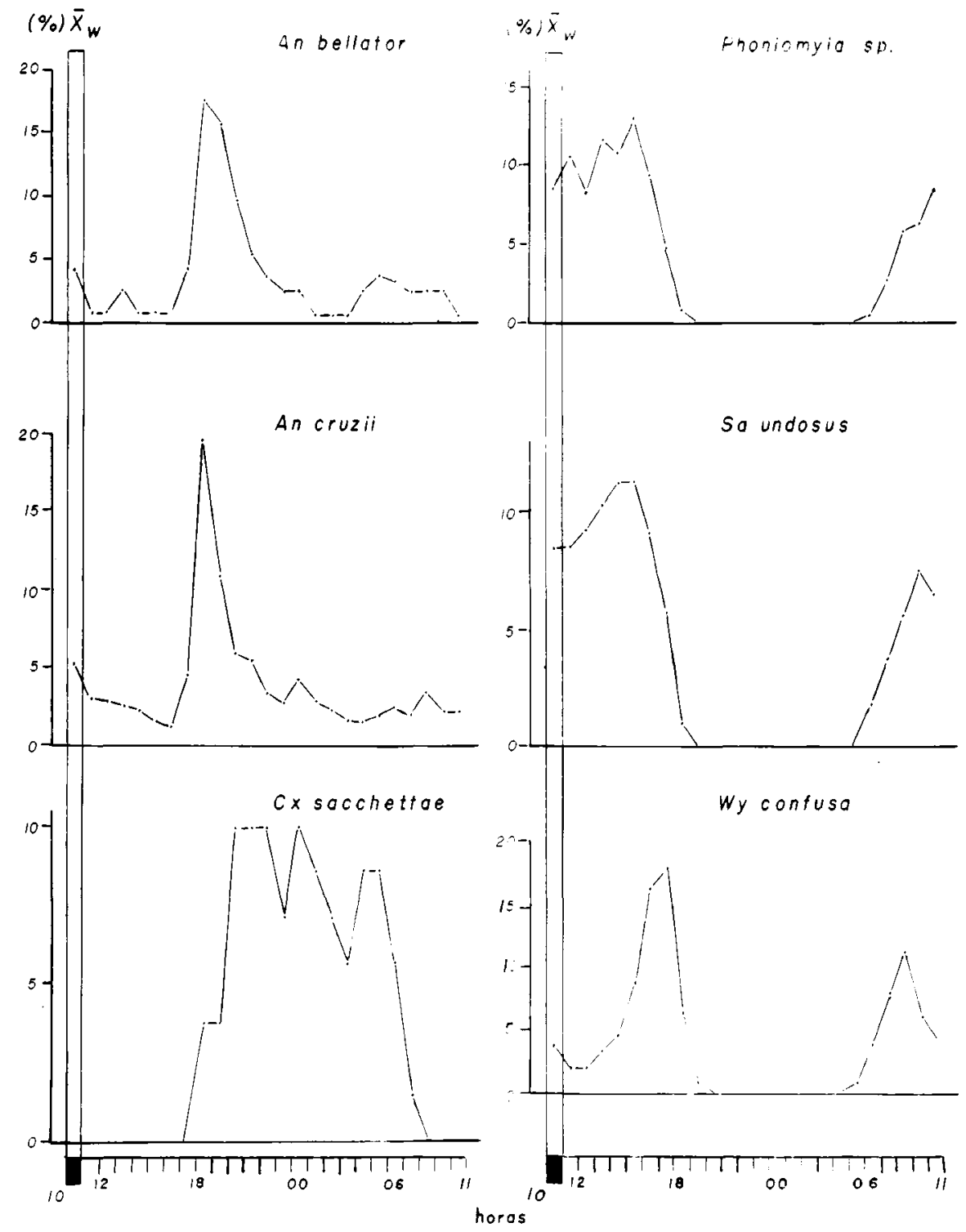

primeira horo (efeito de intrusjo)

Fig. 7 - Atividade horária das espécies mais freqüentes. observada em mata primitiva da encosta. no sitio Itapuã. Distribuição das médias. em percentagens. obtidas mediante encosta. no sitio Itapuã. Distribuição das médıas. em percentagens. obtidas mediante
coletas ininterruptas de 25 horas com isca humana. no período de abril de 1980 a coletas ininterrup ${ }_{\overline{\mathbf{X}}_{w}}$ - médias de Williams. 
FORATTINI, O.P. et al. Observações sobre atividade de mosquitos Culicidae em mata primitiva da encosta no Vale do Ribeira, São Paulo, Brasil. Rev. Saúde públ., S. Paulo, 20: 1-20, 1986.

No que diz respeito à variação horária nas coletas concomitantes com as duas armadilhas tipo Shannon, o período de maior rendimento para os anofelinos Kerteszia correspondeu ao intervalo das 18:00 às 20:00 horas. O gráfico da Figura 8 mostra a distribuição das médias, em percentuais, para as duas espécies, nas horas das coletas em ambos os locais.

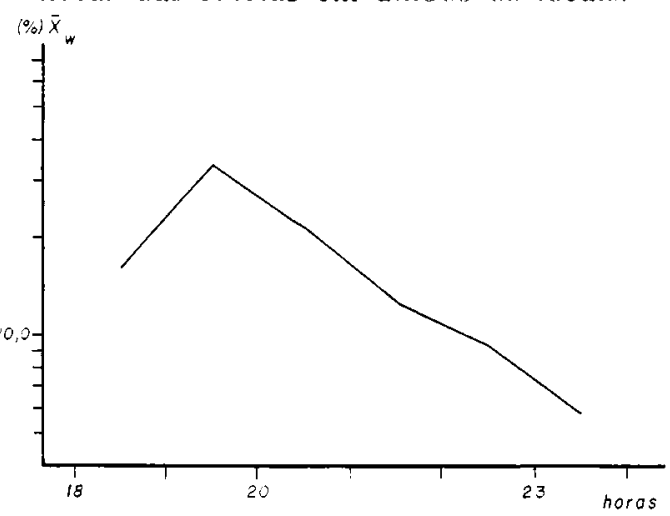

Fig. 8 - Atividade horária de An. bellator e An. cruzii, observada no sítio Itapuā. Distribuição das médias, em percen. tagens, obtidas mediante capturas concomitantes em armadilha tipo Shannon, dentro e fora da mata primitiva da encosta, no horário das $18: 00$ às 24:00 horas, ao longo do pe. ríodo de abril de 1980 a abril de 1982

$\overline{\mathrm{X}}_{\mathrm{w}}$ - médias de Williams.

Atividades crepusculares e pericrepusculares - Dentro da variabilidade regional que ocorre nas diversas épocas do ano, os crepúsculos apresentavam variações, já anteriormente referidas (Forattini e col. $\left.{ }^{6}, 1981\right)$. O vespertino oscila dentro do período das $17: 00$ às $20: 00$ horas, enquanto o matutino o faz no das 4:00 às 7:00 horas. Assim sendo, nas coletas com isca humana procedeu-se ao estudo do comportamento de mosquitos, por ocasião de 91 crepúsculos, 46 dos quais vespertinos e 45 matutinos. Na Tabela 5 encontra-se a distribuição percentual relativa, pelos intervalos crep, dos espaços de tempo utilizados nas capturas parceladas, para ambos os crepúsculos. Os períodos crepusculares propriamente ditos, de maneira geral, oscilaram entre 20 e $30 \mathrm{~min}$ de duração. Assim pois, sendo esse espaço de tempo considerado como o valor da unidade crep, esses períodos corresponderam ao intervalo de 0,0 1,0 para o vespertino e de $1,0-0,0$ para o matutino. Dentro deles, procurouse observar o comparecimento culicídeo atraído pela isca humana. Os espécimens capturados dentro dos intervalos crep de $-4,00$ a 5,00 , distribuídos simetricamente em torno dos supracitados crepúsculos, estão também representados na Tabela 5, tanto pelos números de indivíduos coletados como pela respectiva média de Williams $\left(\overline{\mathbf{X}}_{\mathrm{w}}\right)$. Pôde-se observar que, para as espécies com atividade praticamente restrita, seja às horas diurnas ou às noturnas, os períodos crepusculares assinalaram, simplesmente, a intensificação ou o decréscimo dessa atividade, conforme o caso. E o que se observou com $C x$. sacchettae e Phoniomyia sp. que se mostraram, noturno e diurno, respectivamente. Aquela espécie revelou a ocorrência de um pico de atividade intracrepuscular vespertina porém sem realce nestas observações. Em relação a $A e$. serratus e $P$ s. ferox, observou-se também o papel crepuscular como marco de decréscimo acentuado ou mesmo cessação de atividade, para o vespertino, e incremento ou início para o matutino. Da mesma forma notou-se, para esses dois mosquitos, picos intracrepusculares matutinos. Quanto aos anofelinos Kerteszia pôde-se observar a ocorrência de nítidos picos de atividades crepusculares situados, pelo menos em sua grande parte, dentro desses períodos, tanto vespertino como matutino. Seja para An. cruzzi, seja embora de maneira menos evidente, para $A n$. bellator, a esses incrementos de atividade sucedeu-se sensível queda imediatamente seguida de um segundo pico, desta vez de caráter pós-crepuscular para ambos os períodos. Os gráficos da Figura 9 fornecem idéia desses aspectos. 
FORATTINI, O.P. et al. Observações sobre atividade de mosquitos Culicidae em mata primitiva da encosta no Vale do Ribeira, São Paulo, Brasil. Rev. Saúde públ., S. Paulo, 20: 1-20, 1986.
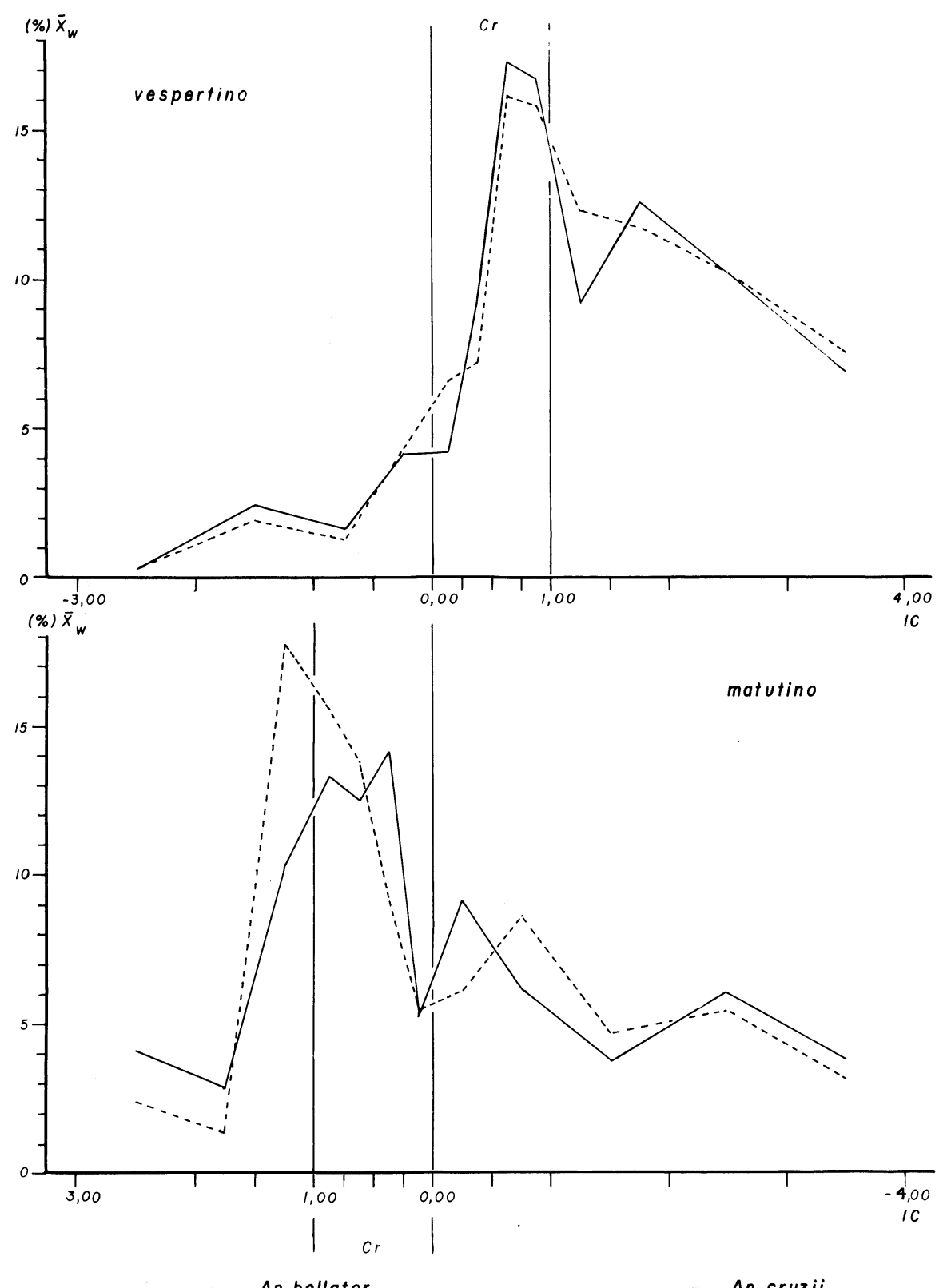

Fig. 9 - Atividades crepusculares e pericrepusculares de anofelinos Kerteszia, observadas com isca humana, em mata primitiva da encosta do sítio Itapuã. Dados distribuidos por isca humana, em mata primitiva da encosta do sítio Itapuã. Dados distribuidos por
intervalos crep, correspondendo os valores de $0.00-1.00$ ao crepúsculo vespertino e os de $1,00-0,00$ ao matutino.

$\mathrm{Cr}$ - período crepuscular

IC - intervalos crep

$\overline{\mathrm{X}}_{\mathrm{K}}$ - médias de Williams, em percentagens. 
FORATTINI, O.P. et al. Observaçōes sobre atividade de mosquitos Culicidae em mata primitiva da encosta no Vale do Ribeira, São Paulo, Brasil. Rev. Saúde públ., S. Paulo, 20: 1-20, 1986.

Dominância e variação sazonal - Levando-se em consideração a ocorrência em todas as horas de coleta, ou seja, tanto no período noturno como no diurno, destacam-se nesse particular os representantes do subgênero Kerteszia. Embora com oscilações, a atividade desses anofelinos não sofreu interrupção, mantendo-se ao longo do horário das capturas (Fig. 7). Assim é que, distribuindo-se o percentual de dominância de Berger-Parker (Southwood ${ }^{16}$, 1978) no conjunto das espécies ou grupos mais frequientes, e por tipo de coleta, foram obtidos os seguintes resultados globais (\%) para as duas espécies:

Isca Armadilha tipo Shannon humana na mata no aberto

$\begin{array}{crrr}\text { An. bellator } & 4,7 & 3,5 & 4,0 \\ \text { An. cruzii } & 74,0 & 93,4 & 95,1 \\ \text { Total } & 78,7 & 96,9 & 99.1\end{array}$

Pôde-se ver pois a franca dominância anofélica, em especial modo do segundo desses mosquitos. Excluindo-se, nas coletas com isca humana, os dados referentes à primeira hora, a distribuição horária da dominância de $A n$. cruzii revelouse praticamente total no período noturno, ou seja, das 18:00 às 07:00, durante o qual praticamente manteve-se acima de $75,0 \%$. Tal aspecto confirmou-se nas capturas com as duas armadilhas tipo Shannon que operaram no horário das 18:00 às 24:00 horas, e onde esse anofelino foi o mosquito expressivamente dominante, oscilando entre 88,9 e $95,9 \%$. Por sua vez, a distribuição mensal da dominância e das médias de Williams $\left(\overline{\mathrm{X}}_{w}\right)$ referentes a esse anofelino, revelou franco predomínio sobre as demais populações, mesmo nos meses de menor atividade culicídea, ou seja, no período de maio a agosto. Os gráficos da Figura 10 destinam-se a ilustrar esses resultados, nos três tipos de coleta empregados.

\section{COMENTÁRIOS}

Como aspecto geral, a composição da fauna culicídea, encontrada nesta pesquisa, foi análoga à registrada em outras áreas da floresta parenifólia higrófila da encosta, ou seja, do relevo acidentado que caracteriza o Sistema da Serra do Mar, e encontrado na região meridional do Brasil (Forattini e col. ${ }^{4}, 1968$ ). Todavia, embora se mantenha a feição qualitativa dessa composição, o mesmo não se pode dizer da quantitativa, uma vez que a dominância e as espécies mais frequientes apresentam apreciável variação. Em se tratando de ambiente primitivo, deve-se considerar como mínima, ou mesmo inexistente, a influência de eventual atividade antrópica, mas presente e atuante a de fatores outros, de caráter regional ou mesmo local. Parece fora de dúvida que a mata primitiva perenifólia higrófila costeirr constitui o habitat ao qual se encontrar 1 adaptadas várias populações de culicídeos. No caso da presente pesquisa, a destacada dominância de Án. cruzii, ao menos nos três métodos da coleta empregados, poderá ser explicada pela sua elevada adaptação a esse ambiente. E que, por sua vez, se traduz por considerável ecletismo tanto na atividade dos adultos como nas oviposições, em vários níveis e situações desse meio flòrestal (Veloso e col. ${ }^{18}$, 1956; Veloso ${ }^{17}$, 1958). O mesmo não ocorre com $A n$. bellator, com menor valência ecológica nesse ambiente e, assim, tendendo a se apresentar circunscrito a áreas costeiras ou de planícies não florestadas, ou revestidas de vegetação tipo restinga ou mesmo secundária (Rachou e col. ${ }^{1+}, 1958$ ). De resto, neste último caso, as modificações introduzidas pelo homem, dando lugar a alterações na dominância das populações de mosquitos, parece perdura- 
FORATTINI, O.P, et al. Observações sobre atividade de mosquitos Culicidae em mata primitiva da encosta no Vale do Ribeira, São Paulo, Brasil. Rev. Saúde públ., S. Paulo, 20: 1-20, 1986.
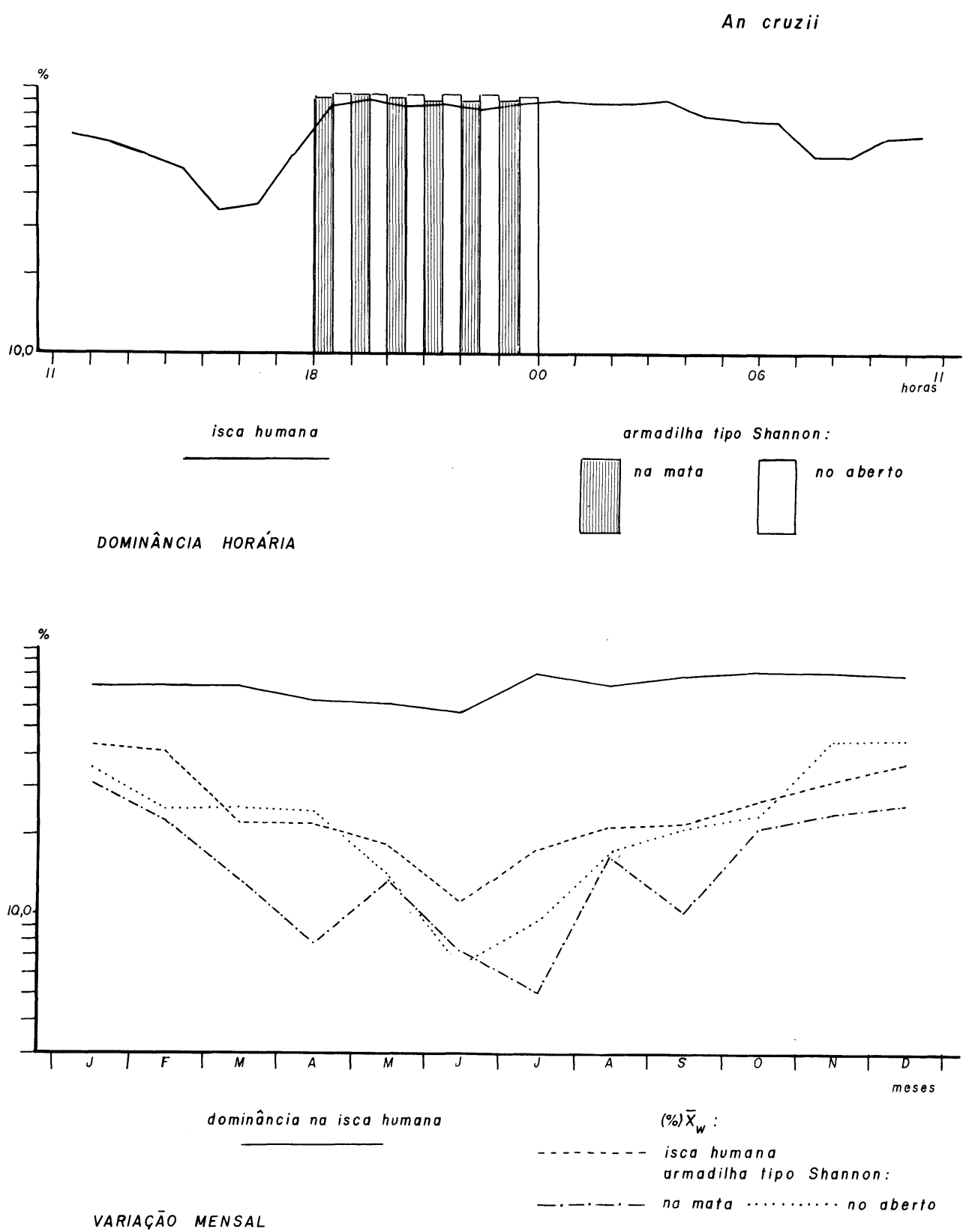

Fig. 10 - Distribuição horária e mensal da dominância de An. cruzii, bem como a variação sazonal com os três tipos de coleta. $\overline{\mathbf{X}}_{\mathrm{w}}=$ médias de willtams. 
FORATTINI, O.P. et al. Observações sobre atividade de mosquitos Culicidae em mata primitiva da encosta no Vale do Ribeira, São Paulo, Brasil. Rev. Saúde públ., S. Paulo, 20; 1-20, 1986.

rem por tempo considerável. Assim é que, a pouca expressividade de $A n$. cruzii, em observações realizadas na Serra dos Orgãos, Estado do Rio de Janeiro, poderia ser explicada pelo fato de se tratar de região não propriamente primitiva, mas sim já modificada e posteriormente objeto de reflorestamento cujo início data da segunda metade do século passado (Alonso ${ }^{1}, 1977$ ). Tratando-se pois de área alterada que, em que pese o tempo decorrido, provavelmente ainda não atingiu o climax que se observa na floresta perenifólia primitiva. Isso permite compreender a baixa frequiência de $A$ n. cruzii, em contraste com a significante presença de Ae. scapularis nessas observações (Guimarães e Arlé9, 1984; Guimarães e col. ${ }^{10}, 1985$ ). Assim pois, o caráter primitivo da floresta onde foram realizadas as observações aqui relatadas, permite entender a dominância daquele anofelino, a qual se torna praticamente absoluta no período noturno, e persiste, sem alteração significante, durante todo o ano, mesmo nos meses de menor atividade, como se pode observar pelos gráficos da Figura 10.

Por sua vez, e como para caracterizar a natureza primitiva do local das presentes observações, pôde-se registrar o baixo comparecimento de $A$ e. scapularis nos vários tipos de captura utilizados. Como se referiu no parágrafo anterior, confirmase assim o caráter de população dotada de acentuada adaptabilidade aos ambientes artificialmente alterados onde, constantemente, tem sido assinalada de maneira significante e chegando a apreciável nível de dominância (Rachou e col. ${ }^{14}, 1958$; Forattini e col. ${ }^{6}, 1981$; Oliveira ${ }^{12}, 1984$ ). Ainda no que respeita à composição específica, convirá registrar a ocorrência, ainda que discreta, de $C x$. sacchettae, $P s$. limitados às coletas com isca humana. Finalmente é de se ponderar sobre a presença, embora inexpressiva e como representantes de grupos de acentuado interesse epidemiológico, de $\mathrm{Hg}$. capricornii e $\mathrm{Hg}$. leucocelaenus (Tabela 2). Dessa maneira, a análise da composição específica e da dominância resultantes destes métodos de coleta permitiu caracterizar, no que tange à fauna culicídea assim observada, o ambiente primitivo da floresta perenifólia higrófila do relevo acidentado. As diferenças a esse respeito podem ser apreciadas verificando-se os resultados obtidos em ambiente intensamente modificado pela atividade humana e relatados em trabalho anterior (Forattini e col. ${ }^{6}, 1981$ ).

As características dos ritmos nictimerais das várias populações seguiram, em linha geral, o que se observou em outras regiões (Forattini e col. ${ }^{6}, 1981$ ). Dentre as espécies mais frequientes (Tabela 1), apresentaram comportamento essencialmente diurno as representantes de Sabethini e Ps. ferox, e noturno o $C x$. sacchettae. Quanto aos anofelinos Kerteszia revelaram atividade contínua durante as 24 horas de coleta com isca humana, porém mostrando nítido pico de incremento por ocasião das horas crepusculares vespertinas correspondentes, ao intervalo entre as 17:00 e 20:00 (Fig. 7). O mesmo não foi tão evidente por ocasião das $04: 00$ às $07: 00$, horas crepusculares matutinas.

Contudo, a análise dos intervalos crepusculares propriamente ditos revelou a ocorrência de atividade incrementada durante os períodos crepusculares (Tabela 5). No caso da espécie noturna $C x$. sacchettae manteve-se a feição eocrepuscular do seu ciclo nictemeral com o desencadeamento vespertino correspondendo ao intervalo crep 0,5 a 1,0. Para $A e$. serratus e $P$ s. ferox, essencialmente diurnos, esse fenômeno ocorreu no intervalo 
FORATTINI, O.P. et al. Observaçōes sobre atividade de mosquitos Culicidae em mata primitiva da encosta no Vale do Ribeira, São Paulo, Brasil. Rev. Saúde públ., S. Paulo, 20: 1-20, 1986.

1,00 a 0,5 do crepúsculo matutino. Verificou-se assim o caráter eocrepuscular desses ciclos. Todavia, a exemplo do já observado em outra área, o início pós-crepuscular, vespertino ou matutino, conforme as espécies noturnas ou diurnas acima citadas, coincide com a elevação da curva de atividade. Ressalte-se, porém, que no caso de $A e$. serratus e Ps. ferox pêde-se observar nítido incremento isolado, ocorrendo imediatamente após os picos endocrepusculares matutinos, e mais evidente para a primeira dessas espécies. Esse fenômeno fornece aspecto bimodal à essa curva crepuscular, com maior intensidade para o segundo pico. Tal aspecto que, de outra maneira, se verificou também com os representantes de Kerteszia, poderia receber o nome de ritmo paracrepuscular. A existência de ondas endocrepusculares podem ser atribuídas à ação de estímulos provavelmente de ordem microclimática. Onde porém pôde-se obter evidências outras, foi em relação aos representantes de Kerteszia. Com efeito, como foi mencionado, a simples atividade horária não permitiu mais do que a revelação de um pico de atividade incrementada, por ocasião do crepúsculo vespertino, ou seja, no período das 17:00 às 20:00 horas. Contudo, a análise com o emprego dos intervalos crep permitiu evidenciar um segundo pico correspondente ao intervalo matutino das 04:00 às 07:00 horas. A observação dos gráficos representadós na Figura 9 permite verificar, em ambos os períodos crepusculares propriamente ditos, a existência de nítidos picos endocrepusculares abrangendo o intervalo vespertino 0,5 a 1,0 e o matutino 1,0 a 0,5 . Tais incrementos de atividade nẩo se continuam, de imediato, com elevação ou diminuição contínua da curva. Verifica-se, porém, que sofrem brusca queda para, logo a seguir, darem lugar a outros dois picos, desta vez pós-crepusculares, ou seja, nos intervalos 1,5 a 2,0 para o vespertino e de 0,0 a $-0,5$ para o matutino. Esse ritmo que, como se mencionou pode ser denominado de paracrepuscular, de aspecto bimodal, mostrou-se mais evidente em $A n$. cruzii, embora tenha sido igualmente apresentado por $A n$. bellator e de maneira bastante visível.

A explicação para esses picos endo e paracrepusculares, deve ser buscada na influência, não apenas de fatores endógenos, mas também exógenos. Entre estes sobressai a variação de luminosidade, ao lado das flutuações macro e principalmente microclimáticas. De qualquer maneira, essas feições no caso dos dois supracitados anofelinos, revestem-se de apreciável significado epidemiológico, ao se levar em conta a atividade humana nas proximidades da floresta durante as horas crepusculares vespertinas.

No que concerne à distribuição mensal, a grande dominância de $A n$. cruzii fez com que os dados apresentados se limitassem a essa espécie (Fig. 10). Pôde-se verificar o decréscimo de sua presença nos três tipos de coleta por ocasião do período mais frio e seco e que compreende os meses de junho a agosto. Todavia, como já se assinalou, sem diminuir a sua dominância sobre os demais culicídeos capturados. De resto, a ocorrência desse mosquito mantém-se durante todos os meses do ano, a exemplo do que foi observado em outras regiões.

\section{CONCLUSÕES}

1 - Em mata primitiva perenifólia higrófila da encosta, do Sistema da Serra do Mar, no Vale do Ribeira, as coletas com o emprego de isca humana e de armadilhas tipo Shannon revelaram composição da fauna culicídea caracterizada por destacada dominância de anofelinos Kerteszia.

2 - Dentre essas espécies anofélicas sobressaiu $A n$. cruzii, que revelou ativi- 
FORATTINI, O.P. et al. Observações sobre atividade de mosquitos Culicidae em mata primitiva da encosta no Vale do Ribeira, São Paulo, Brasil. Rev. Saúde públ., S. Paulo, 20: 1-20, 1986.

TABELA 5

Distribuiçăo percentual $(\%)$ das capturas, parceledas, nos intervalos crep e das espécies mais freqitentes, em mata primitiva da encosta no sítio Itapuã, correspondente aos crepúsculos com isca humana no período de abril de 1980 a abril de 1982 .

\begin{tabular}{|c|c|c|c|c|c|c|c|c|c|c|c|c|c|c|c|c|}
\hline \multicolumn{17}{|c|}{ Crepúsculo Vespertino (*) } \\
\hline \multirow{2}{*}{\multicolumn{2}{|c|}{ Intervalos crep }} & \multirow[b]{2}{*}{$\%$} & \multicolumn{2}{|c|}{ Ae. serratus } & \multicolumn{2}{|c|}{ An. bellator } & \multicolumn{2}{|c|}{ An. cruzil } & \multicolumn{2}{|c|}{ Cx. sacchettae } & \multicolumn{2}{|c|}{$P h$. sp } & \multicolumn{2}{|c|}{ Ps. ferox } & \multicolumn{2}{|c|}{$\boldsymbol{T}$} \\
\hline & & & $N$ & $\bar{x}_{w}$ & $N$ & $\bar{X}_{w}$ & $N$ & $\bar{x}_{w}$ & $N$ & $\bar{x}_{w}$ & $N$ & $\bar{x}_{v}$ & $N$ & $\bar{x}_{w}$ & $N$ & $\bar{x}_{w}$ \\
\hline$-4,001-$ & $-3,00$ & 2,90 & 23 & 0,1 & 4 & + & 123 & 0,3 & 1 & + & 61 & 0,2 & 14 & + & 226 & 0,6 \\
\hline$-3,001-$ & $-2,00$ & 4,35 & 32 & 0,1 & 5 & + & 59 & 0,1 & - & - & 95 & 0,2 & 64 & 0,1 & 255 & 0,5 \\
\hline$-2,001-$ & $-1,00$ & 6,04 & 71 & 0,1 & 55 & 0,1 & 736 & 0,9 & 3 & + & 62 & 0,1 & 83 & 0,1 & 1010 & 1,3 \\
\hline$-1,00 \mid-$ & $-0,50$ & 4,59 & 35 & 0,1 & 19 & 0,1 & 378 & 0,6 & 1 & + & 12 & + & 27 & 0,1 & 472 & 0,9 \\
\hline$-0,501-$ & 0,00 & 4,35 & 13 & 0,2 & 7 & 0,2 & 135 & 1,6 & 2 & + & 9 & 0,1 & 8 & 0,2 & 174 & 2,3 \\
\hline $\int 0,001-$ & 0,25 & 11,11 & 6 & 0,1 & 45 & 0,3 & 530 & 1,6 & 3 & + & 3 & + & 18 & 0,1 & 605 & 2,1 \\
\hline $0,25 \mid-$ & 0,50 & 11,84 & 15 & 0,1 & 42 & 0,3 & 808 & 3,6 & 2 & + & 2 & + & 24 & 0,1 & 893 & 4,1 \\
\hline 0,50 & 0,75 & 17,15 & 7 & + & 143 & 0,7 & 1587 & 6,6 & 9 & 0,1 & 1 & + & 12 & 0,1 & 1759 & 7,5 \\
\hline$(0,75)-$ & 1,00 & 15,22 & 1 & + & 134 & 0,7 & 1361 & 6,3 & 4 & + & - & - & 3 & + & 1503 & 7,0 \\
\hline 1,00 & 1,50 & 2,90 & 2 & + & 140 & 0,5 & 1996 & 3,5 & 5 & + & 1 & + & 2 & + & 2146 & 4,0 \\
\hline 1,50 & 2,00 & 6,28 & 2 & + & 232 & 0,5 & 2653 & 4,8 & 23 & 0,1 & - & 一 & 1 & + & 2911 & 5,4 \\
\hline $2,001-$ & 3,00 & 4,35 & 3 & + & 206 & 0,4 & 2341 & 3,9 & 33 & 0,1 & - & - & 1 & + & 2584 & 4,4 \\
\hline $3,00,1-$ & 4,00 & 5,07 & 10 & + & 199 & 0,3 & 1954 & 2,6 & 104 & 0,1 & 3 & + & 3 & + & 2273 & 3,0 \\
\hline $4,00 \vdash$ & 5,00 & 3,86 & 7 & + & 121 & 0,2 & 1064 & 1,6 & 23 & 0,1 & - & - & 1 & + & 1216 & 1,9 \\
\hline Total & & 100,00 & 227 & 0,8 & 1352 & 4,3 & 15725 & 38,0 & 213 & 0,5 & 249 & 0,6 & 261 & 0,8 & 18027 & 45,0 \\
\hline
\end{tabular}

\begin{tabular}{|c|c|c|c|c|c|c|c|c|c|c|c|c|c|c|c|c|c|c|c|}
\hline \multicolumn{20}{|c|}{ Crepúsculo Matutino (**) } \\
\hline \multirow{2}{*}{\multicolumn{3}{|c|}{ Intervalos crep }} & \multirow[b]{2}{*}{$\%$} & \multicolumn{2}{|c|}{ Ae. serratus } & \multicolumn{2}{|c|}{ An. bellator } & \multicolumn{2}{|c|}{ An. cruzii } & \multicolumn{2}{|c|}{ Cx. socchettae } & \multicolumn{2}{|c|}{$P h . \mathrm{sp}$} & \multicolumn{2}{|c|}{ Ps. ferox } & \multicolumn{2}{|c|}{$\mathbf{T}$} & \multicolumn{2}{|c|}{ Total } \\
\hline & & & & $N$ & $\overline{\bar{x}}_{w}$ & $N$ & $\bar{x}_{10}$ & $N$ & $\overline{\bar{X}_{w}}$ & $N$ & $\overline{\bar{x}_{\infty}}$ & $N$ & $\bar{x}_{w}$ & $N$ & $\bar{X}_{w}$ & $N$ & $\overline{\bar{x}_{w 0}}$ & $N$ & $\overline{\bar{X}}_{*}$ \\
\hline \multirow{14}{*}{$\mathrm{Cr}$} & $-4,001-$ & $-3,00$ & 2,22 & 5 & + & 7 & + & 80 & 0,3 & 1 & + & 12 & 0,1 & 9 & + & 114 & 0,4 & 340 & 1,0 \\
\hline & $-3,00$ & $-2,00$ & 4,69 & 12 & + & 26 & 0,1 & 322 & 0,6 & 11 & + & 11 & + & 8 & + & 390 & 0,7 & 645 & 1,2 \\
\hline & $-2,00 \mid-$ & $-1,00$ & 5,19 & 11 & + & 26 & + & 196 & 0,3 & 22 & + & 7 & + & 4 & + & 266 & 0,3 & 1276 & 1,6 \\
\hline & $-1,00 \mid-$ & $-0,50$ & 5,19 & 8 & + & 28 & 0,1 & 240 & 0,6 & 12 & + & 1 & + & 7 & + & 296 & 0,7 & 768 & 1,6 \\
\hline & $-0,50 \mid-$ & 0,00 & 6,17 & 6 & 0,1 & 10 & 0,1 & 146 & 0,8 & 12 & 0,1 & 1 & + & 2 & + & 177 & 1,1 & 351 & 3,4 \\
\hline & $(0,00)-$ & 0,25 & 11,11 & 3 & + & 7 & 0,1 & 84 & 0,5 & 7 & 0,1 & - & - & - & + & 101 & 0,7 & 706 & 2,8 \\
\hline & $|0,25|-$ & 0,50 & 12,10 & 2 & + & 12 & 0,1 & 230 & 1,3 & 19 & 0,1 & - & - & 2 & + & 265 & 1,5 & 1158 & 5,6 \\
\hline & $0,50 \mid-$ & 0,75 & 17,28 & 5 & + & 27 & 0,1 & 324 & 1,1 & 20 & 0,1 & - & - & 2 & + & 378 & 1,3 & 2137 & 8,8 \\
\hline & $(0,75)-$ & 1,00 & 14,32 & 1 & + & 28 & 0,2 & 277 & 1,2 & 18 & 0,1 & - & - & 1 & + & 325 & 1,5 & 1828 & 8,5 \\
\hline & $1,00 \mid-$ & 1,50 & 4,69 & 4 & + & 57 & 0,2 & 375 & 0,9 & 46 & 0,2 & - & - & 1 & + & 483 & 1,3 & 2629 & 5,3 \\
\hline & 1,50 & 2,00 & 4,20 & - & - & 4 & + & 84 & 0,3 & 41 & 0,1 & 6 & + & 1 & + & 136 & 0,4 & 3047 & 5,8 \\
\hline & 2,00 & 3,00 & 5,43 & - & - & 14 & + & 473 & 0,4 & 35 & 0,1 & - & - & - & - & 522 & 0,5 & 3106 & 4,9 \\
\hline & $3,00 \mid-$ & 4,00 & 3,70 & - & - & 8 & + & 136 & 0,3 & 65 & 0,1 & 1 & + & - & - & 210 & 0,4 & 2483 & 3,4 \\
\hline & $4,001-$ & 5,00 & 3,70 & 3 & + & 18 & + & 240 & 0,5 & 115 & 0,1 & - & - & 1 & + & 377 & 0,6 & 1593 & 2,5 \\
\hline \multicolumn{3}{|c|}{ Total } & 100,00 & 60 & 0,1 & 272 & 1,0 & 3207 & 9,1 & 424 & 1,1 & 39 & 0,1 & 38 & + & 4040 & 11,4 & 22067 & 56,4 \\
\hline \multicolumn{20}{|c|}{$\begin{array}{l}\text { (*) }^{*} 46 \text { coletas. } \\
\left(\text { (*) }^{*} 45 \text { coletas. }\right. \\
\overline{\mathrm{X}}_{\bar{*}} \text { medias de Williams. } \\
+\quad \text { valores de } \overline{\mathrm{X}}_{\mathrm{w}} \text { inferio } \\
\mathrm{Cr} \text { periodo crepuscular }\end{array}$} \\
\hline
\end{tabular}


FORATTINI, O.P. et al. Observações sobre atividade de mosquitos Culicidae em mata primitiva da encosta no Vale do Ribeira, São Paulo, Brasil. Rev. Saúde públ., S. Paulo, 20: 1-20, 1986.

dade contínua para a isca humana, no período das 24 horas.

3 - Tanto An. cruzii como An. bellator mostraram nítidos picos endocrepusculares, vespertino e matutino, aos quais se segue, de imediato, pico de menor intensidade. Tal feição pode caracterizar a ocorrência de ritmo paracrepuscular.

4 - Mostrou-se evidente a influência crepuscular no desencadeamento da atividade culicídea. No caso de $C x$. sacchettae foi possível detectar ritmo eocrepuscular.
Em Ae. serratus e Ps. ferox houve alguma tendência para apresentar ritmo paracrepuscular, embora com aspecto limitado ao crepúsculo matutino.

5 - A dominância de An. cruzii manteve-se durante todos os meses do ano, mesmo naqueles em que se apresentou com menor densidade.

6 - Tal atividade de $A n$. cruzii, aliada à sua densidade, reafirma a importância epidemiológica desse mosquito nos ambientes intra e extraflorestais desse ecossistema.

FORATTINI, O.P. et al. [Observations on mosquito activity in primitive highland rain forest in the Ribeira Valley, S. Paulo, Brazil]. Rev, Saude públ,, S. Paulo, 20: 1-20, 1986.

ABSTRACT: With fortnightly rhythm, 25-hour catches of Culicidae mosquitoes were carried out, at ground level, with human bait, in a primitive rain forest in a highland relief area of the Ribeira Valley region, S. Paulo, Brazil. Besides this, regular simultaneous catches employing Shannon traps were made within and outside the forest environment. Results obtained are presented and discussed. An. cruzii proved a highly dominant species and $A n$. bellator also showed ininterrupted daily activity, increasing at night. They showed too, a clear peak of biting activity during the dusk crepuscular period, sustaining their activity outside the forest environment. During the dawn crepuscular period these two species showed a peak too, and for both crepuscular periods the peaks were immediately followed by other secondary ones, of lower intensity. The name paracrepuscular is suggested for this type of rhythm. $C x$. sacchettae presented an essentially nocturnal pattern with eocrepuscular rhythm, while $A e$. serratus and $P s$. ferox presented a diurnal one, with some evidence of paracrepuscular activity. The epidemiological importance of $A n$. cruzii for the transmission of infections, mainly malaria, and its role for the biogeographical characterization of this primitive ecossystem is emphasized.

UNITERMS: Culex, Ecology. Ribeira Valley, SP, Brazil. Anopheles cruzii. Anopheles bellator.

\section{REFERÊNCIAS BIBLIOGRÁFICAS}

1. ALONSO, M.T.A. Vegetação. In: Fundação IBGE, Geografia do Brasil: região Sudeste. Rio de Janeiro, 1977. v. 3, p. 91-118.

2. CALISHER, C.H. et al. Isolations of near Alpha - and Bunyaviruses of southern Brazil: proposed reclassification of serogroups. In: Simpósio Internacional sobre Arbovirus dos Trópicos e Febres $\mathrm{He}$ morrágicas, Belém, Pará, 1980. Rio de Janeiro, Academia Brasileira de Ciências, 1982. p. 355-62.
3. CALISHER, C.H, et al. Identification of a new venezuelan equine encephalitis virus from Brazil. Amer. J. trop. Med. Hyg., 31:1260-72, 1982.

4. FORATTINI, O.P. et al. Investigaçōes sobre o comportamento de formas adultas de mosquitos silvestres no Estado de São Paulo, Brasil. Rev. Saúde públ., S. Paulo, 2:111 73, 1968.

5. FORATTINI, O.P. et al. Estudos ecológicos sobre mosquitos Culicidae no sistema da Serra do Mar, Brasil. - Obser- 
FORATTINI, O.P. et al. Observações sobre atividade de mosquitos Culicidae em mata primitiva da encosta no Vale do Ribeira, São Paulo, Brasil. Rev. Saúde públ., S. Paulo, 20: 1-20, 1986.

vações no ambiente extradomiciliar. Rev. Saúde públ., S. Paulo., 12:297-325, 1978.

6. FORATTINI, O.P. et al. Observações sobre atividade de mosquitos Culicidae, em mata residual no Vale do Ribeira, S. Paulo, Brasil. Rev. Saúde públ., S. Paulo, 15-557-86,1981.

7. FORATTINI, O.P. \& SALLUM, M.A.M. A new species of Culex (Melanoconion) from southern Brazil (Diptera: Culicidae). Rev. Saúde públ., S. Paulo, 19:171$82,1985$.

8. GAFFIGAN, T.V. \& WARD, R.A. Index to the second supplement to "A catalog of the mosquitoes of the world", with corrections and additions. Mosq. Syst., 17:52-63, 1985.

9. GUIMARÃES, A.E. \& ARLE, M. Mosquitos no Parque Nacional da Serra dos Órgãos, Estado do Rio de Janeiro, Brasil. Mem. Inst. Oswaldo Cruz, 79:309. 33, 1984.

10. GUIMARÃES, A.E. et al. Mosquitos no Parque Nacional da Serra dos Órgãos, Estado do Rio de Janeiro, Brasil. Mem. Inst. Oswaldo Cruz, 80:171-85, 1985.

11. LOPES, O. de S. et al. Emergence of a new arbovirus disease in Brazil. III Isolation of Rocio virus from Psorophora ferox (Humboldt, 1819). Aemr. J. Epidem., 113:122-5, 1981.

12. OLIVEIRA, R.L, de Alguns aspectos da ecologia dos mosquitos (Diptera: Culicidae) de uma área de planície (Granja Calaboia), em Jacarepaguá, Rio de Janeiro. I - Freqüência comparativa das espécies em diferentes ambientes e métodos de coleta. Mem. Inst. Oswaldo Cruz, 79:479-90, 1984.

13. OLIVEIRA, R.L. de \& DEANE, L.M. What is Anopheles allopha (Lutz \& Peryassú, 1921) (Diptera: Culicidae)? Mem. Inst. Oswaldo Cruz, Rio de Janeiro, 79:509-10, 1984

14. RACHOU, R.G. et al. Alguns dados sobre o comportamento de mosquitos de Ponta Grossa (Florianópolis, Santa Catarina). Rev. bras. Malar., 10:417-27, 1958.

15. SIRIVANAKARN, S. \& JAKOB, W.L. Culex (Melanoconion) sacchettae, a new species from State of São Paulo, Brazil (Diptera: Culicidae). Mosq. Syst., 13: $191-4,1981$.

16. SOUTHWOOD, T.R.E. Ecological methods. 2nd ed. London, Chapman and Hall, 1978.

17. VELOSO, H.P. Considerações gerais sobre os biótopos dos anofelíneos do subgênero Kerteszia. Mem. Inst. Oswaldo Cruz, 56:163-79, 1958.

18. VELOSO, H.P. et al Delimitação ecológica dos anofelíneos do subgênero Kerteszia na região costeira sul do Brasil. Mem. Inst. Oswaldo Cruz, 54:517-48, 1956.

19. WARD, R.A. Second supplement to "A catalog of the mosquitoes of the world" (Diptera: Culicidae). Mosq. Syst., 16: 227-70, 1984.

Recebido para publicação em 30/10/1985 Aprovado para publicação em 18/12/1985 